\title{
Cancer Prevention Through Employ of Appropriate Diet in Daily Schedule
}

\section{Shukati Malik* and Sajid Khan}

Department of Bioinformatics, Muhammad Ali Jinnah University Islamabad, Pakistan

\begin{abstract}
The aim of study is to evaluate the relationship between diet and cancer prevention. Cancer is one of the leading causes of death throughout the world. This study provides a summary of nutritional factors and their relation to risk of major cancers based on current data. We realize that supplemental nutrients may have different health effects than nutrients in food and that lifestyle behaviors such as smoking can modify risks. This research will provides new and better understanding of the complex physiological action of isolated supplements in health and disease.
\end{abstract}

Keywords: Diet and cancer hindrance; Fruits and vegetables; Relationship of diet schedule; Cancer

\section{Background}

During the 1990s, enthusiasm swelled for increasing consumption of fruits and vegetables with the expectation that this would substantially reduce the risk of many cancers [1]. Many studies have been conducted about dietary interventions aimed at preventing cancer. It has been estimated that 30-40 percent of all cancers can be prevented by of appropriate diet in daily schedule [2]. However, food selection is also known to vary by season [3], and general food consumption trends over long time periods are observed in most populations [4-6].

The effort against cancer is one of the greatest challenges of mankind. In industrialized countries Obesity, nutrient sparse foods such as concentrated sugars and refined flour products that contribute to impaired glucose metabolism (which leads to diabetes), low fiber intake, consumption of red meat, and imbalance of omega 3 and omega 6 fats all contribute to excess cancer risk. Intake of flax seed, especially its lignin fraction, abundant portions of fruits and vegetables will lower cancer risk. Ascorbic acid has partial benefits orally, but could be very beneficial intravenously. Supplementary use of oral digestive enzymes and probiotics also has merit as anticancer dietary measures [2].

Food habit information was obtained through a modified diet history method [7-9]. When a diet is compiled according to the guidelines here it is likely that there would be at least a $60-70$ percent decrease in breast, colorectal, and prostate cancers, and even a 40-50 percent decrease in lung cancer, along with similar reductions in cancers at other sites. Such a diet would be conducive to avoid cancer and would favor recovery from cancer as well [2].

The common characteristic of all cancers is abnormal cell proliferation, development and death. Diet history methods are interviewer administered quantitative diet methods which typically use cross-check frequency lists to estimate usual food consumption frequencies, and photographic aids, food models or household measuring devices to estimate usual portion size. The field of investigation of the role of nutrition in the cancer process is very broad. It is becoming clearer as research continues that nutrition plays a major role in cancer. $30-40$ percent of all cancers can be prevented by appropriate diets, physical activity, and maintenance of appropriate body weight. It is likely to be higher than this for some individual cancers [10].

\section{Introduction}

\section{Role of nutrition in cancer prevention}

A diet rich in selenium and Omega- 3 has a preventive role in prostate carcinoma. An excessive intake of food is one of the main factors of neoplastic risk and it is proved that obesity is a condition that predisposes the development of malignant neoplasm. Overweight is responsible for $14 \%$ of cancer deaths in men and $20 \%$ in women [11]. The major causative factors of cancer and their percentage has been explained (Table 1).

\section{Fruits and citrus}

One of the most important messages of modern nutrition research is that a diet rich in fruits protects against cancer. The greatest message is that this same diet protects against almost all other diseases, to, including cardiovascular disease and diabetes. There are many mechanisms by which fruits are protective, and an enormous body of research supports the recommendation for people to eat more fruits and vegetables. Overall, a high intake of fruits probably reduces the risks of cancers of the oral cavity, esophagus, stomach and colorectum [2].

\begin{tabular}{|l|l|}
\hline Tobacco & $30 \%$ \\
\hline Diet & $35-60 \%$ \\
\hline Air/Water Pollution & $13 \%$ \\
\hline Alcohol & $17 \%$ \\
\hline Radiation & $3 \%$ \\
\hline Medications & $2 \%$ \\
\hline
\end{tabular}

Table 1: Some major causative factors of cancer and their percentage for causing cancer.

*Corresponding author: Shukati Malik and Sajid Khan, Department of Bioinformatics, Muhammad Ali Jinnah University Islamabad, Pakistan, E-mail: drsimalik@jinnah.edu. pk, sajiddilazakkhan@gmail.com

Received September 16, 2011; Accepted November 02, 2011; Published November 04, 2011

Citation: Malik S, Khan S (2011) Cancer Prevention Through Employ of Appropriate Diet in Daily Schedule. J Cancer Sci Ther S16: 001. doi:10.4172/19485956.S16-001

Copyright: @ 2011 Malik S, et al. This is an open-access article distributed under the terms of the Creative Commons Attribution License, which permits unrestricted use, distribution, and reproduction in any medium, provided the original author and source are credited. 
At that time, however, the available literature was based largely on case-control studies, and subsequent prospective studies have not supported important protective effects for cancers of the lung and breast, and have suggested that the reduction in risk for colorectal cancer may be modest. These discordant results, which add to concerns about the potential for bias in case-control studies, also suggest the need for some caution regarding conclusions about intake of fruits and vegetables and the risks of oral, esophageal and stomach cancers, which have not been adequately examined in large prospective studies. Furthermore, none of the dietary studies of stomach cancer has controlled adequately for infection by H. pylori, which is a potential confounding variable [2].

Citrus fruit include Orange, Grapefruit, Lemon, and Mondrian. Studies have suggested that photochemical compounds in citrus fruit block tumor growth by direct action on the cancerous cells, restricting their ability to reproduce. Such fruits consumption, whether in, the form of whole fruit or juice, supplies the body with an incomparable source of specific anticancer molecules, while also providing the essential daily requirements of many vitamins and minerals [12].

\section{Cruciferous vegetables}

Cruciferous vegetables (broccoli, cauliflower, cabbage, Brussels sprouts) contain sulforophane, which has anti cancer properties. Generally, a high intake of vegetables possibly reduces the threat of cancers of the jaws .A case control study in China found that intake of cruciferous vegetables, measured by urinary secretion of isothiocyanates, was inversely related to the risk of breast cancer; the quartile with the maximum intake only had $50 \%$ of the hazard of the lowest intake group [2].

\section{Flax seed and fish oils (omega 3 fa)}

Coupled with reduction of heart disease, Preclinical studies show conflicting results for omega 3/lignan effects on tumour growth and metastasis. Evidence is insufficient to recommend dietary supplementation of flax or fish oils to reduce risk of cancer recurrence or to improve prognosis [11].

\section{Garlic}

It has observed that cancer, antibacterial, or antifungal effects of garlic useful in preventing the cancer. Large doses potentially harmful stomach pain, gas, vomiting, and inhibition of platelet formation [13].

\section{Ginger}

Has antinausea properties and is useful in management of motion sickness, when nausea is triggered by a local effect (I.e. acts on stomach). Chemotherapy induced nausea is CNS stimulated response and therefore often requires specific medication to block/prevent stimulation of the emetic response. Taste and aroma of ginger may be calming. Large doses of ginger have been shown to have antiplatelet activity [13].

\section{Tea}

Epidemiologic evidence mixed regarding cancer risk amongst black or green tea drinkers.Tea contain high levels of catechins and polyphenols known to affect cancer cell growth in vitro.Very little research has been done on the effects of tea consumption among cancer survivor. Moderate amounts of green or black tea can be considered safe and helpful in preventing the cancer [14].

\section{Berries}

Most berries are an exceptionally abundant source of several classes of polyphenols that posses anticancer potential ellagic acid, anthocyanidins, and proanthocyanidins. Eating cranberries should be preferred over drinking cranberry juice [12].

\section{Macronutrients}

Carbohydrates, protein, and fat each contribute energy to the diet, so excess energy intake resulting from overconsumption of any or a combination of these macronutrients may influence cancer risk. However, the question of whether individual macronutrients increase risk independent of energy balance remains controversial [15].

For example, in intervention studies of low-fat diets under is caloric conditions, calories from fat are replaced with calories from carbohydrate and/or protein. Other nutrients are likely to change as well. As a result, differentiating the effect of reduced fat intake from these other changes is difficult. Likewise, simply adding fat to the diet cannot be separated from adding energy (or the consequent weight gain). Epidemiologic studies of macronutrients must therefore carefully consider total energy and other energy-bearing nutrients in the analysis [15-17].

\section{Fat}

The results of studies of fat consumption in relation to cancer have been inconsistent, particularly across study designs. Much of the interest regarding nutrition and cancer originated from ecologic studies, in which countries with high per capita fat intake were shown to have higher rates of cancers of the breast $[18,19]$, colon, and prostate $[20,21]$ than countries with lower fat intakes. As important confounders were not measured and controlled for in these analyses, dietary fat may also have been merely a marker for a true causal factor (e.g. reproductive factors). Animal studies also contributed to the hypothesis that fat caused cancer but fat intake was likely to be a surrogate of energy intake [22]. Fat intake has been hypothesized to increase the risk of breast and prostate cancer by modulating sex hormone levels, and to increase colon cancer risk by stimulating mutagenic secondary bile acid secretion. Early dietary guidelines, based on these data, emphasized fat reduction for cancer prevention [23].

\section{Carbohydrates}

Coincident with the strong emphasis on lowering dietary fat over the past several decades, grain and sugar consumption in the US increased markedly. Carbohydrates are heterogenous and probably have varying effects on health and disease [24].

Dietary carbohydrates include starches (e.g. bread, pasta, other grains), non-starch polysaccharides (the major component of dietary fiber), and sugars. Carbohydrates with a high glycemic index [25] are associated with higher postprandial blood glucose and insulin [26,27], and higher fasting insulin levels in insulin-resistant states [25], and are thus hypothesized to increase cancer risk. However, epidemiologic studies currently provide limited support for a direct role of diets high in glycemic load (which takes the total carbohydrate intake into account) in cancer development.

Some studies of colon and breast cancer [26,27] did not find an association between diets high in glycemic load or sugar and cancer, while others did [28-30]. The inconsistencies may result from difficulties in measuring the glycemic potential of diet, given the 
importance of meal composition, for example. However, glycemic load measured from FFQs has strongly predicted the risk of coronary heart disease [31] and type II diabetes [32]. Glycemic load may increase the risk particularly among susceptible subgroups; one study observed increased risk of breast cancer only among those with elevated BMI [33,34]. Pancreatic cancer risk was increased by $53 \%$ with a high glycemic diet in a study of women, and by $170 \%$ among those who were sedentary and overweight. More work is needed, as most studies of carbohydrates and cancer risk have not considered carbohydrate quality. Nonetheless, the existing data suggest that abnormal glucose and insulin metabolism is important in carcinogenesis, especially in obese, sedentary individuals [35].

\section{Meat}

Evidence for a role of meat consumption in increasing cancer risk, especially of the colon, rectum, and prostate, has been fairly consistent over time and across study designs. Countries with high per capita meat consumption were shown to have higher incidence of colon cancer than those with low meat consumption. Two meta-analyses of meat and colorectal cancer risk were recently published, one including 13 prospective studies [36], and the other including results from 34 casecontrol studies and 14 prospective cohort studies. The former reported a significant $12-17 \%$ increase in risk associated with each daily $100 \mathrm{~g}$ increment of all meat or red meat intake (slightly more than $3 \mathrm{oz}$ ), and a $49 \%$ increased risk for each $25 \mathrm{~g}$ increment of processed meats (about one slice) [37]. In the other meta-analysis, the investigators reported a $24 \%$ increase in risk associated with each daily $120 \mathrm{~g}$ increment of red meat intake, and a 36\% increase in risk for each $30 \mathrm{~g}$ increment of processed meat $[38,39]$.

\section{Summary}

The evidence for a role of diet in cancer prevention is continually evolving as new studies accumulate. This study provides a summary of nutritional factors and their relation to risk of major cancers based on current data. The factors listed would undoubtedly vary if summarized by other authors, but the evolving and expanding is does demonstrate substantial progress since Doll and Peto's [40,41] report. For example, leading hypotheses even 10 years ago centered on total calories, dietary fat, specific factors in fruits and vegetables (including bcarotene and dietary fiber), and vitamins A, E, and C [42]. These hypotheses have been tested, extended, and clarified, and some have been refuted. A role for positive energy balance and obesity in carcinogenesis has been strengthened, while a specific role of dietary fat has weakened. Fruits and vegetables still appear to be protective for several cancers, but as a whole are weaker determinants than originally thought. Specific photochemical (e.g. folate, lycopene, flavonoids flavonoids, and fiber) continue to be actively studied, although distinguishing protective elements in plant foods is a daunting task. We appreciate that better supplemental nutrients may have different health effects than nutrients in food (which may be due to dose, form, or presence of other nutrients in food), and that lifestyle behaviors such as smoking can modify risks. Intervention studies have ruled out a specific protective effect against cancer among smokers for b-carotene, and against a role of certain isolated dietary fibers in reducing recurrent adenomas. However, this research has opened new doors for understanding the complex physiological action of isolated supplements in health and disease. Conversely, calcium supplements did confer modest reduction of adenoma recurrence in two polyp prevention trials. Early studies of gene-diet interactions suggest an important potential for public health impact, especially for folate-metabolizing enzymes, but have generally been inconsistent and too small to examine the multitude of potential interactions in complex biological pathways.

\section{Acknowledgment}

We would like to thank Ms Z. Khalid \& S. Zahra for helping in the proof reading of the paper.

\section{References}

1. Block G, Patterson B, Subar A (1992) Fruit, vegetables, and cancer prevention: a review of the epidemiological evidence. Nutr Cancer 18: 1-29.

2. Michael SD (2004) A review of the evidence for an anti-cancer diet. Nutrition Journal 19: 3-19

3. Willett W (1998) Nutritional Epidemiology. Monographs in Epidemiology and Biostatistics New York Oxford, Oxford University Press 30: 101-147.

4. Helsing $E$ (1993) Trends in fat consumption in Europe and their influence on the Mediterranean diet. Eur J Clin Nutr 47: S4-S12

5. Senauer B, Asp E, Kinsey J (1993) Food trends and the changing consumer St. Paul MN, Eagan Press

6. Kromhout D, de Lezenne-Coulander C, Obermann de Boer GL, van Kampen Donker M, Goddijn E, et al. (1990) Changes in food and nutrient intake in middle-aged men from 1960 to 1985 (the Zutphen Study). Am J Clin Nutr 51 : 123-129.

7. Stallone DD, Brunner EJ, Bingham S (1997) Dietary Assessment in Whitehall II: The influence of reporting bias on apparent socioeconomic variation in nutrient intakes. Eur J Clin Nutr 51: 815-825.

8. Fanelli MT, Stevenhagen KJ (1986) Consistency of energy and nutrient intakes of older adults: 24-hour recall vs 1-day food record. J Am Dietet Assoc 86 665-667.

9. Goldberg GR, Black AE, Jebb SA, Cole TJ, Murgatroyd PR, et al. (1991) Critical evaluation of energy intake data using fundamental principles of energy physiology: 1. Derivation of cut-off limits to identify under-recording. Eur J Clin Nutr 45: 569-581.

10. Albanes D, Jones DY, Schatzkin A, Micozzi MS, Taylor PR (1988) Adult stature and risk of cancer. Cancer Res 48: 1658-1662.

11. Duilio D, Sergio DT, Salvatore S, Margherita G, Roberto C (2006) Diet and Cancer. Acta Biomed 77: 118-123.

12. Jin D, Russell JM (2010) Plant Phenolics: Extraction, Analysis and Their Antioxidant and Anticancer Properties. Molecules 15: 7313-7352.

13. Jiang X, Williams KM, Liauw WS, et al. (2005) Effect of ginkgo and ginger on the pharmacokinetics and pharmacodynamics of warfarin in healthy subjects. Br J Clin Pharmacol 59: 425-432.

14. Gong Y, Xiao-Ou S, Honglan L, Wong-Ho C, Bu-Tian J, et al. (2007) Prospective Cohort Study of Green Tea Consumption and Colorectal Cancer Risk in Women. Cancer Epidemiol Biomarkers Prev 16: 1219-1223.

15. Alberts DS, Martinez ME, Roe DJ, Guillen-Rodriguez JM, Marshall JR, et al. (2000) Lack of effect of a high-fiber cereal supplement on the recurrence of colorectal adenomas. Phoenix Colon Cancer Prevention Physicians' Network. N Engl J Med 342: 1156-1162.

16. Aldecruetz H (2002) Phyto-oestrogens and cancer. Lancet Oncol 3: 364-373.

17. Ambrosone CB, Freudenheim JL, Sinha R, Graham S, Marshall JR, et al (1998) Breast cancer risk, meat consumption and N-acetyltransferase (NAT2) genetic polymorphisms. Int J Cancer 75: 825-830.

18. Ames BN, Gold LS, Willett WC (1995) The causes and prevention of cancer Proc Natl Acad Sci USA 92: 5258-5265.

19. Arab L, Steck-Scott S, Bowen P (2001) Participation of lycopene and betacarotene in carcinogenesis: defenders, aggressors, or passive bystanders? Epidemiol Rev 23: 211-230.

20. Armstrong B, Doll R (1975) Environmental factors and cancer incidence and mortality in different countries, with special reference to dietary practices. Int $J$ Cancer 15: 617-631. 
Citation: Malik S, Khan S (2011) Cancer Prevention Through Employ of Appropriate Diet in Daily Schedule. J Cancer Sci Ther S16: 001. doi:10.4172/1948-5956.S16-001

21. Augustin LSA, Dal Maso L, La Vecchia C, Parpinel M, Negri E, et al. (2001) Dietary glycemic load and colorectal cancer risk. Ann Oncol 12: 1533-1538.

22. Baron JA, Beach M, Mandel JS, van Stolk RU, Haile RW, et al. (1999) Calcium supplements for the prevention of colorectal adenomas. Calcium Polyp Prevention Study Group. N Engl J Med 340: 101-107.

23. Baron JA, Cole BF, Mott L, Haile R, Grau M, et al. (2003) Neoplastic and antineoplastic effects of beta-carotene on colorectal adenoma recurrence: results of a randomized trial. J Natl Cancer Inst 95: 717-722.

24. Barreto AM, Schwartz GG, Woodruff R, Cramer SD (2000) 25-Hydroxyvitamin D3, the prohormone of 1,25-dihydroxyvitamin D3, inhibits the proliferation of primary prostatic epithelial cells. Cancer Epidemiol Biomarkers Prev 9: 265270.

25. Barrett JH, Smith G, Waxman R, Gooderham N, Lightfoot T, et al (2003) Investigation of interaction between $\mathrm{N}$-acetyltransferase 2 and heterocyclic amines as potential risk factors for colorectal cancer. Carcinogenesis 24: 275282

26. Bingham SA (1987) Nutr Abstr Rev 57: 705-743

27. Bingham SA, Day NE, Luben R, Ferrari P, Slimani N, et al. (2003) Dietary fibre in food and protection against colorectal cancer in the European Prospective Investigation into Cancer and Nutrition (EPIC): an observational study. Lancet 361: 1496-1501.

28. Bingham SA, Hughes R, Cross AJ (2002) Effect of white versus red meat on endogenous $\mathrm{N}$-nitrosation in the human colon and further evidence of a dose response. J Nutr 132: 3522S-3525S.

29. Bingham SA, Luben R, Welch A, Wareham N, Khaw KT, et al. (2003). Are imprecise methods obscuring a relation between fat and breast cancer? Lancet 362: 212-214.

30. Block G, Patterson B, Subar A (1992) Fruit, vegetables, and cancer prevention a review of the epidemiological evidence. Nutr Cancer 18: 1-29.

31. Blot WJ, Li JY, Taylor PR, Guo W, Dawsey S, et al. (1993) Nutrition intervention trials in Linxian, China: supplementation with specific vitamin/minera combinations, cancer incidence, and disease-specific mortality in the general population. J Natl Cancer Inst 85: 1483-1492.
32. Blount BC, Mack MM, Wehr CM, MacGregor JT, Hiatt RA, et al. (1997) Folate deficiency causes uracil misincorporation into human DNA and chromosome breakage: implications for cancer and neuronal damage. Proc Natl Acad Sci USA 94: 3290-3295.

33. Bonithon-Kopp C, Kronborg O, Giocosa A, Rath U, Faivre J (2000) Calcium and fibre supplementation in prevention of colorectal adenoma recurrence: randomised intervention trial. European Cancer Prevention Organisation Study Group. Lancet 356: 1300-1306.

34. Bostick RM (1997) Human studies of calcium supplementation and colorectal epithelial cell proliferation. Cancer Epidemiol Biomarkers Prev 6: 971-980.

35. Branca F, Hanley AB, Pool-Zobel B, Verhagen H (2001) Biomarkers in disease and health. Br J Nutr 85: S55-S92.

36. Bretherton-Watt D, Given-Wilson R, Mansi JL, Thomas V, Carter N, et al. (2001) Vitamin D receptor gene polymorphisms are associated with breas cancer risk in a UK Caucasian population. Br J Cancer 85: 171-175.

37. Brockton N, Little J, Sharp L, Cotton SC (2000) N-acetyltransferase polymorphisms and colorectal cancer: a HuGE review. Am J Epidemiol 151 846-861.

38. Burkitt DP (1971) Epidemiology of cancer of the colon and rectum. Cancer 28 3-13.

39. Calle EE, Rodriguez C, Walker-Thurmond K, Thun MJ (2003) Overweight obesity, and mortality from cancer in a prospectively studied cohort of U.S adults. N Engl J Med 348: 1625-1638.

40. Campbell IG, Baxter SW, Eccles DM, Choong DY (2002) Methylenetetrahydrofolate reductase polymorphism and susceptibility to breas cancer. Breast Cancer Res 4: R14.

41. Carroll KK (1975) Experimental evidence of dietary factors and hormonedependent cancers. Cancer Res 35: 3374-3383.

42. Chan JM, Stampfer MJ, Ma J, Rimm EB, Willett WC, et al. (1999) Supplementa vitamin $E$ intake and prostate cancer risk in a large cohort of men in the United States. Cancer Epidemiol Biomarkers Prev 8: 893-899. 